\title{
VARIEDADES \\ DOCUMENTOS LEGALES EN FUENTES ANDALUSÍES
}

\author{
Maribel FIERRO \\ CSIC. Madrid
}

Es conocido que algunos pactos establecidos entre distintos poderes políticos de la península Ibérica han llegado hasta nosotros a través de su preservación en crónicas históricas, diccionarios biográficos o incluso fuentes literarias ${ }^{1}$, por no mencionar su preservación en archivos cristianos ${ }^{2}$. No es tan conocido que en fuentes andalusíes pertenecientes a diversos géneros podemos rastrear una serie de documentos legales cuyo escaso número se compensa por su relevancia para suplir la ausencia de archivos capaces de suministrarnos material comparable al que disponen los historiadores medievalistas. Hay que hacer la salvedad de que la época nazarí constituye una excepción en lo que se refiere a las carencias derivadas de la no preservación de archivos. Diversas circunstancias, una de ellas el interés de los conquistadores cristianos para conservar determinada documentación de los territorios conquistados, han hecho posible que hoy día dispongamos de una cantidad no desdeñable de documentos de época nazarí. A Luis Seco de Lucena debemos una primera aproximación a este corpus $^{3}$. Su labor tiene continuación en un proyecto que se lleva a cabo actualmente en Granada ${ }^{4}$. Los documentos legales procedentes de comunidades mudéjares y moriscas constituyen también un área específica en la que no me voy a detener, así como tampoco en los procedentes del contexto mozárabe toledano.

Se ha producido un notable avance en el estudio de los formularios notariales andalusíes que nos ofrecen los modelos teóricos de los documentos de tipo legal. Sin retrotraerme a los inicios del estudio de este género, me limitaré a seña-

\footnotetext{
${ }^{1}$ Vid. mi artículo «La falsificación de la historia: al-Yasa ' b. Ḥazm y su Kitāb al-mugrib», AlQantara, XVI (1995), 15-38, donde analizo el supuesto amán concedido por 'Abd al-Rahmān I a las gentes de Castilla. Doy referencias a la bibliografía existente sobre el pacto de Tudmīr (nota 14), así como señalo por primera vez la conservación del pacto entre Ibn Hūd al-Mustanșir bi-llāh e Ibn 'Iyāọ en una fuente biográfica (nota 69).

${ }^{2}$ Vid. Burns, R. I., y Chevedden, P. W. (with a contribution by De Epalza, M.), Negotiating Cultures. Bilingual Surrender Treaties in Muslim-Crusader Spain under James the Conqueror, Leiden, 1999.

${ }^{3}$ Vid. a título de ejemplo su obra Documentos arábigo-granadinos, ed. y trad., Madrid, 1961.

4 «Repertorio Documental Arábigo-Granadino. Edición, traducción y estudio», Investigador Principal: Camilo Álvarez de Morales, años 2000-2002 (PB98-0690).
} 
lar que entre las aportaciones más recientes tenemos la edición de las obras de Ibn Mugī (m. 459/1067) ${ }^{5}$ y de al-Ŷazīīi (m. 585/1189) ${ }^{6}$, así como la (esperada) traducción del formulario de Ibn al- ${ }^{\circ}$ Ațāar (m. 399/1009) ${ }^{7}$. Frente a este avance, la bibliografía relativa a los documentos que se conservan citados en otro tipo de fuentes para épocas anteriores a la nazarí se caracteriza por ser una bibliografía escasa y dispersa que va siendo necesario juntar y comentar, sin olvidar que todavía no se ha llevado a cabo una labor de rastreo sistemático en las fuentes andalusíes para reunir un corpus de los documentos legales que en ellas se citan, bien reproduciendo el texto, bien haciendo referencia a su existencia ${ }^{8}$. Como muestra del tipo de documentos que se pueden encontrar si se realizase ese rastreo sistemático, valgan tres ejemplos.

1. Documento de manumisión de Bazī', esclavo originario de Oviedo manumitido por 'Abd al-Raḥmān I y abuelo del famoso alfaquí y tradicionista Muḥammad b. Waḍ̣āḥ al-Qurțubī (m. 287/900). Ese documento ha sido preservado por Ibn H̦ārit al-Jušanī (m. 361/971) ${ }^{9}$. El texto del documento corresponde a uno recogido en un papiro egipcio ${ }^{10}$.

${ }^{5}$ Al-Muqni ‘ fi 'ilm al-šsurūts, ed. Aguirre Sádaba, F. J., Madrid, 1994 (Fuentes ArábicoHispanas, 5). A F. J. Aguirre Sádaba debemos un reciente artículo en el que se recoge una abundante bibliografía sobre documentos contenidos en formularios notariales: «Notas acerca de la proyección de los kutub al-watấ'iq en el estudio social y económico de al-Andalus», Miscelánea de Estudios Árabes y Hebraicos. Sección Árabe e Islam, 49 (2000), 3-30.

${ }^{6}$ Al-Maqșad al-mahmūid fi taljịs al-'uqūd, ed. Ferreras, A., Madrid, 1998 (Fuentes ArábicoHispanas, 23).

${ }^{7}$ Ibn al-'Atțār, Formulario notarial y judicial andalusi del alfaquí y notario cordobés $m$. 399/1009, introducción, estudio y traducción anotada Chalmeta, P., y Marugán, M., Madrid: Fundación Matritense del Notariado, 2000.

${ }^{8}$ Dentro de la convocatoria de proyectos del Ministerio de Educación y Cultura del año 2000, presenté como Investigadora Principal un proyecto que, con el título «Documentos notariales y judiciales en los tribunales andalusíes» (Ref. BFF2000-1533), pretendía reunir ese corpus como paso previo a su estudio. El proyecto fue denegado por insuficiencias en «Metodología propuesta. Objetivos científicos. Contenido innovador. Distribución y justificación de los recursos económicos solicitados», así como por «Deficiente conocimiento de la bibliografía y estado de la cuestión; imprecisión en la metodología y plan de trabajo; insuficiente información sobre resultados del proyecto análogo anterior». Los otros dos miembros del equipo eran María Arcas Campoy (Universidad de La Laguna) y Alfonso Carmona (Universidad de Murcia), quien había coordinado una Mesa Redonda sobre el tema en el VI Simposio de la Sociedad Española de Estudios Árabes (Tudela, noviembre 1999).

${ }^{9}$ Ajbār al-fuqahä' wa-l-muhadditin, ed. Ávila, M. L., y Molina, L., Madrid, 1992 (Fuentes Arábico-Hispanas, 3), n. ${ }^{\circ}$ 137, p. 122. Vid. al respecto Fierro, M. I., «Bazī', mawlà de 'Abd alRaḥman I, y sus descendientes», Al-Qanțara, VIII (1987), 99-118.

${ }^{10} \mathrm{Vid}$. Crone, P., Roman, provincial and Islamic law, Princeton, 1987, 108-9. Sobre la importancia de los papiros para los documentos legales más antiguos que se conservan, vid. el reciente estudio de Rapoport, Y., «Matrimonial gifts in early Islamic Egypt», Islamic Law and Society, 7 (2000), 1-36. 
2. Contrato matrimonial de Yahyà b. Yahyà al-Laytīin, conservado en una obra del siglo VI/XII y estudiado por Marín, M. ${ }^{11}$.

3. Nombramiento de un alfaquí consultor en el siglo VI/XII ${ }^{12}$.

Estos documentos proceden de diccionarios biográficos $\left(n^{\circ} 1,3\right)$ y de un formulario notarial (n. ${ }^{\circ}$ ). La consulta de compilaciones de fetuas o dictámenes jurídicos muestra que la cosecha que se podría extraer de ellas sería bastante rica. Naturalmente, las propias fetuas constituyen un tipo de documento legal que se archivaba en el dìwān del cadí ${ }^{13}$. Pero dejando de lado las fetuas, para obtener una idea de los documentos que se citan dentro de ellas o que se añaden a ellas basta con consultar la traducción de D. Serrano de los Madāâhib al-hukkām ${ }^{14}$.

La ausencia de material de archivos en las sociedades islámicas pre-modernas es especialmente llamativa si se compara con la abundancia de ese material en las sociedades cristianas de la misma época o en sociedades islámicas como la otomana. ¿A qué se debe esta ausencia? No parece que pueda ser atribuida a una pérdida accidental, ya que es algo característico de prácticamente todas las sociedades islámicas premodernas. El escaso número de documentos administrativos, familiares, judiciales, etc., conservado ha sido explicado recientemente por M. Chamberlain, como indicador de la distinta función que los documentos tenían en las sociedades islámicas premodernas en comparación con las cristianas. En el Occidente latino, los documentos servían para probar privilegios, exenciones, competencias profesionales, precedentes, honores o posesiones. Las naciones, clases, corporaciones, grupos religiosos, familias y facciones dirimían conflictos, tensiones y luchas a través de documentos y tenían, por tanto, interés en preservarlos. En el mundo islámico, parece que los individuos y los diferentes grupos (familiares, religiosos, etc.), no necesitaban preservar los documentos como prueba de estatus hereditario, privilegio o propiedad en la

\footnotetext{
${ }^{11}$ Mujeres en al-Andalus, Madrid, 2000 (Estudios Onomástico-Biográficos de al-Andalus, XI), pp. 367-8 (la cita es de los Wat̄ā'iq de al-Garnātī). Se pueden encontrar referencias a otros documentos en las pp. 137, 265, 322, 325, 337, 347, 354, 366-7, 383, 385, 411, 413, 479 del estudio de Marín.

${ }^{12}$ Carmona, A., «El saber y el poder: cuarenta biografías de ulemas levantinos en época de Ibn Mardanǐs», Estudios Onomástico-Biográficos de al-Andalus, X, Madrid, 2000, 57-129, pp. 123-4.

${ }^{13} \mathrm{La}$ obra de Ibn Sahl al-Ahkām al-kubrà se nutre fundamentalmente de material procedente de archivos judiciales, para lo que ya había un precedente, los Aḥām de Ibn Ziyād. Sobre éstos puede verse ahora Muranyi, M., «Das Kitāb Aḥkām Ibn Ziyād. Uber die Identifizierung eines Fragmentes in Qairawān (Qairawāner Miszellaneen V.)», Z.D.M.G., 148 (1998), 241-260.

${ }_{14} \mathrm{Ibn}$ 'Iyād (m. 575/1179), Madāhib al-hukkām fi nawāzil al-ahkām, trad. Serrano, D., La actuación de los jueces en los procesos judiciales, Madrid, 1998 (Fuentes Arábico-Hispanas, 22).
} 
misma medida en que ello ocurría en el Occidente latino. Sus estrategias de reproducción social no requerían en el mismo grado la utilización de documentos ${ }^{15}$. Ésta, por otro lado, ha estado siempre estrechamente unida al nivel de cultura escrita («literacy»), alcanzado por una sociedad determinada ${ }^{16}$.

Dentro de este contexto, la preservación de los tres documentos arriba reseñados plantea una serie de interrogantes: ¿cuáles son las similitudes y diferencias entre estos documentos y los incluidos en los formularios notariales?, ¿son documentos auténticos?; si lo son, ¿por qué han sido rescatados del olvido?; si no lo son, ¿por qué fueron fabricados y preservados? El proyecto de investigación al que se ha hecho referencia en la nota 8 tenía como objetivo dar respuesta a estas preguntas. Por el momento, me limitaré a esbozar aquí algunas reflexiones, que no considero concluyentes, relativas al caso del documento n. ${ }^{\circ} 1$.

El hecho de que Bazī‘ era un esclavo manumitido y cliente (mawlà) del primer emir omeya está corroborado por todas las fuentes. No es el único caso de establecimiento de clientela por manumisión con un omeya del que tenemos noticia ${ }^{17}$, pero sí es el único documento de manumisión que se ha conservado. Su preservación tiene mucho que ver con el carácter de la fuente en que está incluido. Los Ajbār al-fuqahā' wa-l-muḥadditîn, obra que Ibn Ḥārit al-Jušanī compuso para al-Hakam II, se caracterizan por la riqueza y abundancia de las anécdotas y del material biográfico que acompaña a cada entrada onomástica, aspecto éste que destaca especialmente si se comparan esas entradas con las del diccionario biográfico de Ibn al-Faraḍī ${ }^{18}$. Ibn Ḥārit al-Jušanī no parece haber visto en persona el documento de manumisión, pues dice que fue un ulema anónimo quien le dijo haber leído dicho documento, que se encontraba entre otros documentos de Bazī‘. Ese ulema llamó la atención sobre la formulación tan resumida de las estipulaciones de la manumisión y clientela. La brevedad del docu-

15 Vid. Chamberlain, M., Knowledge and social practice in medieval Damascus, 1190-1350, Cambridge, 1995, 11-21, donde se pueden encontrar referencias bibliográficas a estudios anteriores.

${ }^{16}$ Apenas si hay estudios con respecto a la cultura escrita no sólo por lo que se refiere a alAndalus, sino por lo que se refiere a otras sociedades islámicas premodernas. Una aproximación al tema se encuentra en Fierro, M., «The teaching of the five pillars of Islam in sixth/twelfth century al-Andalus», comunicación presentada en el Workshop «Education and the individual in Mediterranean Muslim societies», Salamanca, 15-17 octubre 1998, dentro del programa de la European Science Foundation «Individual and Society in the Mediterranean Muslim World, Team 1: Forms of belonging and modes of social integration».

${ }^{17}$ Vid. al respecto Fierro, M., «Los mawāli de "Abd al-Rahmān I», Al-Qantara XX (1999), 65-98.

${ }^{18}$ Vid. al respecto Ávila, M. L., «El género biográfico en al-Andalus», Ávila, M. L., y Marín, M. (eds.), Estudios onomástico-biográficos de al-Andalus, VIII. Biografías y género biográfico en el Occidente islámico, Madrid, 1997, 35-52. No hay que olvidar que la obra de Ibn al-Faradī nos ha llegado en su versión resumida. 
mento justifica (aunque ello no se expresa así) el hecho de que ese informante anónimo haya podido memorizarlo y, por tanto, transmitírselo a Ibn Hārit alJušanī. Éste no era de origen andalusí y muchas de las anécdotas que recoge se pueden explicar en parte por la curiosidad que obviamente sentía por la historia de su tierra de adopción, a la que había llegado en el año 312/924 ${ }^{19}$. Ibn Hārit alJušanī fue también miembro de la šūrà en Córdoba y administrador de herencias en Pechina. ¿Pudo verse envuelto en algún proceso judicial en el que se requiriese probar los lazos de clientela existentes entre los omeyas y los descendientes de Ibn Waḍ̣āḥ al-Qurțubī (m. 287/300)? Poco sabemos de éstos a partir de la muerte del hijo de Ibn Waḍ̣āh (falleció en vida de su padre), que parecía destinado a seguir los pasos de su padre en el mundo del saber. Por otro lado, sabemos que los mawālì omeyas adquieren especial relevancia durante la época del califato como grupo social que constituye uno de los fundamentos en los que se apoya la dinastía, llegando a ocupar un lugar específico en las recepciones oficiales ${ }^{20}$. Asegurar la pertenencia al grupo de los mawāli, demostrando el derecho a ella ${ }^{21}$, no podía sino traer beneficios (prestigio, posibles remuneraciones) a los descendientes de la familia de Ibn Waḍ̂āh, personas que no parecen haber destacado por ningún otro motivo, como sí habían hecho sus antepasados: Bazī y al-Hārit b. Bazī en el entorno del ejército y la administración, y Muhammad b. Waḍ̣āh en el mundo del saber. De hecho, entre los asistentes al acto de la bay' $a$ de Hišām II se incluye a un Muhammad b. 'Abdūn b. Fahd, de quien se afirma que era nieto (por parte de madre) de Ibn Waḍ̣āḥ. Si el conocimiento oral por parte de Ibn Hạarit al-Jušanī de la existencia del documento de manumisión de Bazī' tuvo lugar dentro de un contexto en el que se trataba de probar el carácter hereditario de la clientela establecida entre 'Abd al-Rahmān I y Bazī', entonces ello podría indicar un caso en que un documento legal es utilizado por un grupo familiar para asegurarse el acceso a determinados privilegios y honores, función no muy diferente a la que Chamberlain señalaba como una de las propias de los documentos en las sociedades del Occidente latino. Esto quiere decir que todavía seguimos necesitando estudios concretos de la documentación conservada con objeto de poder precisar la función de los documentos en las sociedades islámicas, parafraseando el título del magnífico estudio de Jeanette Walkin ${ }^{21}$.

${ }^{19}$ Es de esperar que el volumen de los E.O.B.A. dedicado a estudiar el contenido de los Ajbār vea pronto la luz.

${ }^{20}$ Barceló, M., «El califa patente: el ceremonial omeya de Córdoba o la escenificación del poder», en Pastor, R.; Kieniewica, I.; García de Enterría, E., et al. (eds.), Estructuras y formas del poder en la historia, Salamanca, 1991, 51-71; Meouak, M., Pouvoir souverain, administration centrale et élite politiques dans l'Espagne umayyade (IIe-VIe/VIIIe-Xe siécles), Helsinki, 1999.

${ }^{21}$ Cf. el caso de Sirāŷ: Fierro, «Los mawālī de 'Abd al-Rahmān I», 79.

${ }^{22}$ Walkin, J., The function of documents in Islamic Law, Albany, 1972. 